\title{
The Association of Ménétrier Disease with Ulcerative Colitis: A Case Report with Implications on the Pathogenesis of Ménétrier Disease
}

\author{
Vien X. Nguyen ${ }^{\mathrm{a}} \quad$ Cuong C. Nguyen ${ }^{\mathrm{a}}$ \\ Jonathan A. Leighton ${ }^{\mathrm{a}}$ Shabana F. Pasha ${ }^{\mathrm{a}}$ Alvin C. Silva $^{\mathrm{b}}$ \\ Jacques P. Heppell ${ }^{d}$ Giovanni De Petris ${ }^{c}$ \\ Departments of a Gastroenterology and Hepatology, ${ }^{\mathrm{b}}$ Radiology and 'Laboratory \\ Medicine/Pathology, Mayo Clinic, Scottsdale, Ariz., and dDepartment of Surgery, \\ Mayo Clinic, Phoenix, Ariz., USA
}

\section{Key Words}

Ménétrier disease - Ulcerative colitis - Transforming growth factor-alpha - Epidermal growth factor receptor . Cetuximab

\begin{abstract}
Ménétrier disease (MD) is a rare hypertrophic condition of the gastric mucosa. The unusual association of MD with ulcerative colitis (UC) has been reported in the literature in eight cases. Transforming growth factor-alpha (TGF-alpha) is overexpressed in UC and appears to play a role in colonic healing and repair. Overproduction of TGF-alpha in murine stomach has been shown to induce gastric hypertrophy similar to MD. It can be hypothesized that increased expression of TGF-alpha may occur in the gastric mucosa in patients with UC and may lead to MD. We report the ninth case of MD associated with UC. The role of TGF-alpha and treatment with cetuximab are discussed.
\end{abstract}

\section{Introduction}

Ménétrier disease (MD) is rare disorder that was first described in 1888 [1]. It is characterized by giant gastric folds that involve the fundus and the body of the stomach with sparing of the antrum, excess mucus production, hypochlorhydria, and hypoproteinemia [2]. Although the pathogenesis is not well understood, epidermal growth factor receptor (EGFR) and its ligand, transforming growth factor-alpha (TGF-alpha), have been implicated. Overexpression of TGF-alpha in the gastric mucosa 
f metallothionein-TGF-alpha transgenic mice induced a condition similar to MD [3] Treatments with various agents including antacids, anticholingic drugs, $\mathrm{H}_{2}$ blockers, proton pump inhibitors, prostaglandins, and prednisone have had inconsistent results [4]. With approval by the FDA for compassionate use, a monoclonal antibody against EGFR, cetuximab, has been used with success in five cases [5]. Despite a clinical response to neutralizing monoclonal antibody therapy, we report a case with no biochemical improvement on cetuximab and its implications on the pathogenesis of MD.

\section{Case Report}

A 33-year-old Hispanic male with a 7-year history of ulcerative colitis (UC) was admitted for chronic vomiting, epigastric pain, iron deficiency anemia, peripheral edema, and protein-losing gastropathy. The hospitalization was complicated by pulmonary embolus and Staphylococcus epidermidis sepsis. Colonoscopy confirmed active UC in the distal colon. Esophagogastroduodenoscopy showed a thick mucous coat on the gastric surface (fig. 1). An abdominal CT scan revealed marked hypertrophic gastric rugae involving the entire fundus, cardia, and body, sparing the antrum (fig. 2 ). Also there was relative loss of haustral markings involving the transverse colon, a finding often seen in chronic UC (fig. 2). On endoscopic ultrasound examination, the echotexture of the gastric mucosa and submucosa appeared grossly abnormal, and gastric wall thickness was $14 \mathrm{~mm}(\mathrm{NL}<5)$. Histopathology demonstrated massive hypertrophy of the foveolar mucosa, glandular cystic dilation, focal smooth muscle penetration into the mucosa, and marked eosinophilia (fig. $)$ ). These findings were consistent with MD. Immunostaining for Helicobacter pylori was positive and the infection was treated with lansoprazole/amoxillin/ clarithromycin $\left(\right.$ Prevpac $^{\circledR}$ ) for two weeks with repeated biopsies negative for H. pylori. Immunostaining for cytomegalovirus (CMV) was negative. UC was eventually controlled with mesalamine and prednisone. Symptoms of MD persisted after promethazine, pantoprazole, prednisone, and octreotide. As part of a single-arm research trial, the patient was treated with four weekly doses of cetuximab. He initially showed clinical and biochemical improvement and elected to continue treatment for 8 months. With cetuximab, the patient's symptoms of nausea, vomiting, and epigastric pain improved. However, over time, cetuximab did not seem to be as effective and the patient continued to have iron deficiency anemia (ferritin $23 \mathrm{ng} / \mathrm{ml}, \mathrm{MCV} 71.5 \mathrm{fl}$, positive gastric occult blood with $\mathrm{pH}>7$ ) and peripheral edema due to the protein-losing gastropathy (albumin $1.5 \mathrm{~g} / \mathrm{dl}$ ). He also experienced a significant infusion reaction to cetuximab. As a result, the patient underwent a total gastrectomy and an esophagojejunostomy with J-tube feeding placement without complications. After one year of follow-up, the patient's symptoms resolved and he continues to be asymptomatic.

\section{Discussion}

The common symptoms of MD include nausea and vomiting, abdominal pain, edema, and weight loss. Peripheral edema is caused by the low oncotic pressure from gastric protein loss [2]. Gastric bleeding with iron deficiency anemia is sometimes seen with this disorder [6]. Increased mucus secretion and hypochlorhydria are due to hyperplasia of mucous cells at the expense of gastric parietal cells. MD also predisposes to sepsis and thromboembolism, which is probably caused by low intravascular volume [5].

A form of MD is associated with CMV in children and with $H$. pylori in adults $[7,8]$. Treating the infection may reverse the disease process. In our case, $H$. pylori eradication had no effect and CMV was negative. Two reported cases were treated successfully with octreotide and five reported cases were successfully treated with cetuximab. The basis for the use of these drugs is that both have been shown to block EGFR $[5,9,10]$. A trial of octreotide (both short- and long-acting forms) for 6 months had no effect in our patient. Our patient initially responded to a one-month course of cetuximab, but symptoms recurred during longer-term treatment with a decline in biochemical parameters. He also experienced an infusion reaction, leading him to undergo elective gastrectomy. 
TGF-alpha is a potent mitogen that stimulates gastric growth and inhibits gastric acid secretion. In transgenic mice, overexpression of TGF-alpha induces hyperplasia of the gastric mucosa resembling MD by binding to EGFR in the stomach [3]. Patients with UC have enhanced TGF-alpha expression in the colonic mucosa [11]. Whether or not a similar condition occurs in the gastric mucosa of patients having both MD and UC is unknown. Our patient had a partial response to cetuximab. We can hypothesize that (1) other ligands beside TGF-alpha may be involved in the pathogenesis of MD, (2) MD consists of distinct stages requiring different treatment (medical vs. surgical), or (3) MD could be the morphological manifestation of diverse disorders with diverse pathogenetic mechanisms.

In conclusion, this case highlights the unusual association of UC with MD. A hypothesis of the mechanisms responsible for this association is suggested. Further studies are necessary to determine whether there are specific molecular defects in MD that may explain the occasional association of these two disorders.

Fig. 1. Endoscopic view of giant gastric folds with thick mucous coat.

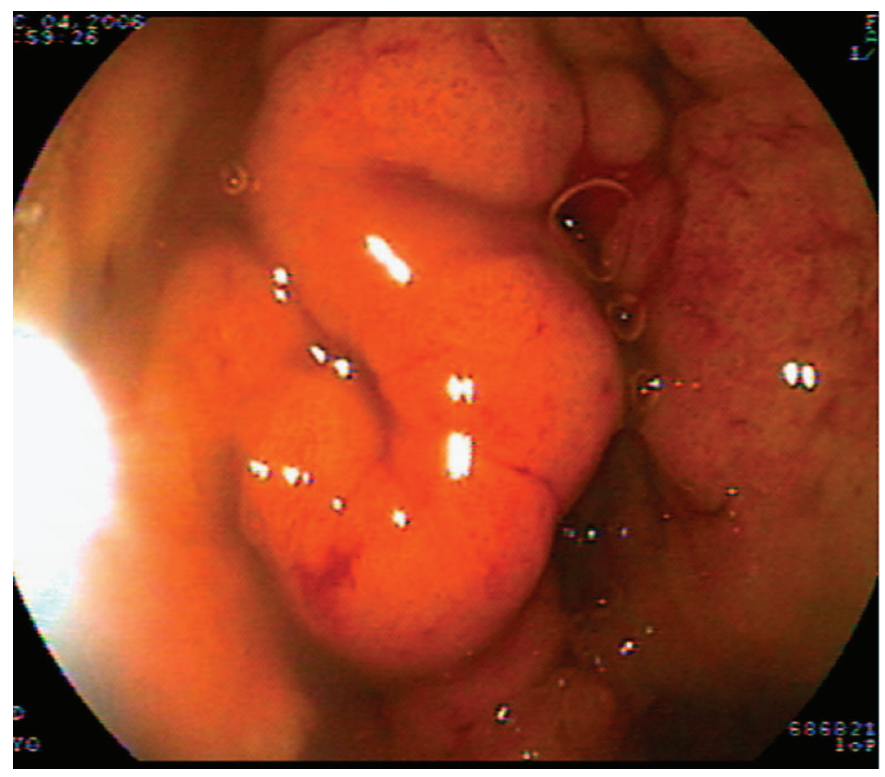




\begin{tabular}{r|l|l|l}
$\begin{array}{r}\text { Case Reports in } \\
\text { Gastroenterology }\end{array}$ & $\begin{array}{l}\text { Case Rep Gastroenterol 2010;4:66-70 } \\
\text { D0I: 10.1159/000255981 }\end{array}$ & Published online: February 19, 2010 & $\begin{array}{l}\odot \text { 2010 S. Karger AG, Basel } \\
\text { ISSN 1662-0631 } \\
\text { www.karger.com/crg }\end{array}$ \\
\hline
\end{tabular}

Fig. 2. Coronal image from contrast-enhanced abdominal CT exam demonstrating giant gastric folds involving the entire fundus, cardia, and body (arrow), with relative sparing of the antrum (large arrowhead). The degree and distribution of fold thickening helps to distinguish this entity from other causes. Note also the nearly denuded appearance of the colon due to long-standing UC (small arrowhead).

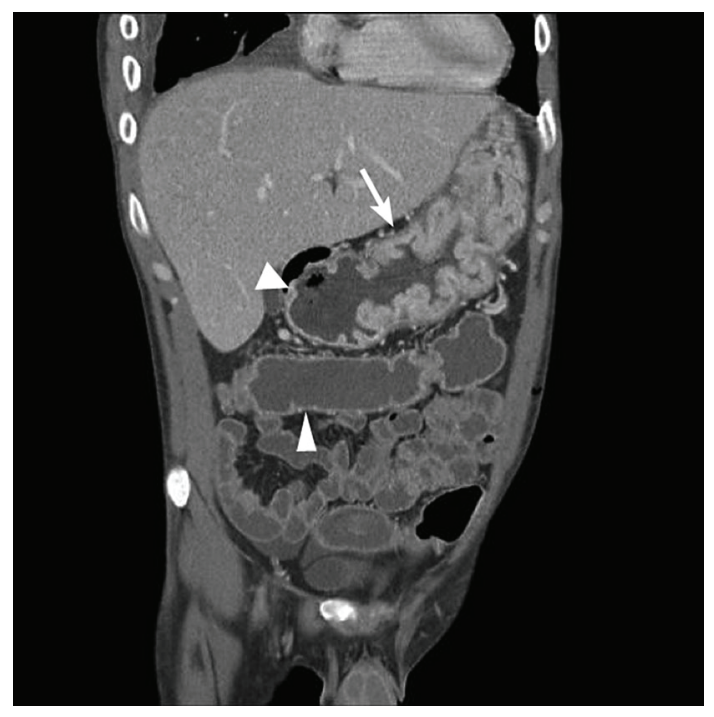

Fig. 3. Hematoxylin-eosin staining of gastric mucosa with foveolar hyperplasia, glandular cystic dilation, focal smooth muscle penetration into the mucosa, and marked eosinophilia.

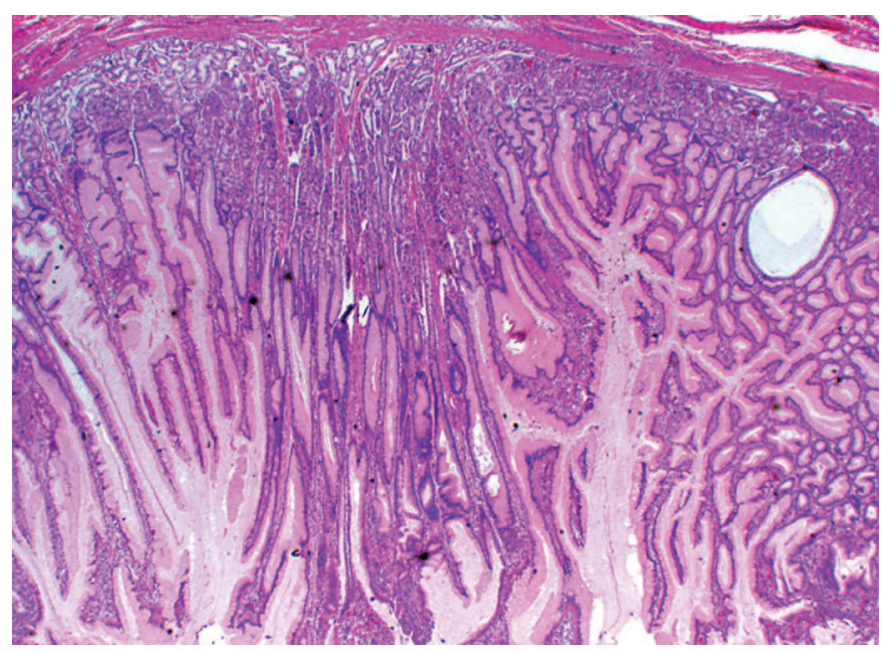




\section{References}

1 Menetrier P: Des polyadenomes gastriques et leur rapport avec le cancer de l'estomac. Arch Physiol Norm Pathol 1888;1:32-55, 236-262.

2 Wolfsen HC, Carpenter HA, Talley NJ: Menetrier's disease: a form of hypertrophic gastropathy or gastritis. Gastroenterology 1993;12:1011-1014.

-3 Takagi H, Jhappan C, Sharp R, Merlino G: Hypertrophic gastropathy resembling Menetrier's disease in transgenenic mice overexpressing transforming growth factor alpha in the stomach. J Clin Invest 1992;90:1161-1167.

4 Kelly DG, Miller LJ, Malagelada JR, Huizenga KA, Markowitz H: Giant hypertrophic gastropathy (Menetrier's disease): Pharmacologic effects on protein leakage and mucosal ultrastructure. Gastroenterology 1982;83:581-589.

5 Coffey RJ, Washington MK, Corless CL, Heinrich MC: Menetrier disease and gastrointestinal stromal tumors: hyperproliferative disorders of the stomach. J Clin Invest 2007;117:70-80.

6 Wilkerson ML, Meschester SC, Brown RE: Menetrier's disease presenting with iron deficiency anemia. Ann Clin Lab Sci 1998;28:14-18.

7 Kovacs AA, Churchill MA, Wood D, Mascola L, Zaia JA: Molecular and epidemiologic evaluations of a cluster of cases of Menetrier's disease associated cytomegalovirus. Pediatr Infect Dis J 1993;12:1011-1014.

-8 Bayerdorffer E, Ritter MM, Hatz R, Brooks W, Ruckdeschel G, Stolte M: Healing of protein losing hypertrophic gastropathy by eradication of Helicobacter pyloriis Helicobacter pylori a pathogenic factor in Menetrier's disease? Gut 1994;35:701704 .

-9 Yeaton P, Frierson HF: Octreotide reduces enteral protein losses in Menetrier's disease. Am J Gastroenterol 1993;88:95-98.

10 Green BT, Branch MS: Menetrier's disease treated with octreotide long-acting relase. Gastrointest Endosc 2004;60:1028-1029.

11 Babyatsky MW, Rossiter G, Podolsky DK: Expression of transforming growth factor alpha and beta in colonic mucosa in inflammatory bowel disease. Gastroenterology 1996;110:975-984. 